\title{
A LAB TASK GROUP FOR REVIEW AND CONTINUOUS IMPROVEMENT OF THIRD AND FOURTH-YEAR LABORATORY COURSES
}

\author{
David Torvi, Scott Noble, Doug Bitner, Melanie Fauchoux, Rob Peace, Rick Retzlaff, Ike Oguocha, \\ Hayden Reitenbach \\ Department of Mechanical Engineering \\ University of Saskatchewan \\ david.torvi@usask.ca
}

\begin{abstract}
Since the mid-1980's, the mechanical engineering program at the University of Saskatchewan has included three core third and fourth-year lab courses, each of which consists of 9-10 individual labs. In 2015 a task group was set up to review these courses, including deliverables, scheduling and links to material in core courses. Since this time, the task group has taken on the major responsibility for continuous improvement of the lab program, including reviewing student evaluations, making changes to labs, and recommending equipment purchases.
\end{abstract}

The task group has also been responsible for a major redesign of the lab program, which will improve delivery and scheduling of labs, alignment with core courses, workload of students, and experience gained by graduate teaching assistants. Smaller apparatus have been designed and built in-house to allow students to gain additional hands-on experience. Labs have been designed to build on one another in order to systematically improve students' general laboratory skills, including the use of data acquisition systems and experimental design. This new approach was used for the first time in ME 328 in 2019-20.

This paper will focus primarily on the role of the task group in continuous improvement, and the lab program redesign. The new ME 328 course is described, along with lessons learned from the first offering. The task group's role in moving to remote labs during COVID-19 is also discussed.

Keywords: laboratories, experiential learning, continuous improvement, hands-on learning, experimental design

\section{INTRODUCTION}

Labs are a critical part of the engineering curriculum, and play a major role in investigation, use of engineering tools and other graduate attributes [1]. Engineering programs often point to labs as being one of their strengths. Feisel and Rosa [4] discuss the history and objectives of engineering labs. They note that relatively little research has been published on labs as compared to other components of courses. Coppens, et al. [2] also noted this lack of research in engineering labs in a more recent paper.

There has been a recognition of the importance of continuing to improve labs, including taking advantage of advances in technology, and ensuring that students get an opportunity to gain hands-on experience. Felder and Brent [5] discuss how lab courses can be better designed to meet ABET criteria, including teaching experimental design and other key skills early in a course, incorporating open-ended experiments (rather than traditional, prescriptive labs), and assigning specific roles to lab group members. Fuhrmann, et al. [6] discuss students' perceptions and improvements in performance after a lab course was changed from a set of individual labs to a series of projects. They also discuss how a blend of individual labs, projects, simulations and remote labs can be utilized within an engineering program. Schkoda, et al. [10] describe a review of their lab program, changes made, and the effectiveness of these changes.

The renewal of individual labs or complete lab courses in Canadian engineering schools has been reported at CEEA conferences and in other engineering education venues. Over the past several years, examples have included having students design and then conduct lab experiments [7] and redesigning a fourth-year mechanical engineering lab course [8]. A laboratory course incorporating both traditional and open-ended labs (which include design or simulation) has been developed to take advantage of the benefits of each approach [11]. The need to move to remote delivery of courses during the COVID-19 pandemic has also resulted in changes to the way in which engineering labs are delivered, some of which may continue after in-person instruction resumes.

In upper years of Canadian mechanical engineering programs labs are typically done in one of two ways: dedicated lab sessions for each core course, or common lab 
courses, which cover this core material and general laboratory skills. Since the mid-1980's the mechanical engineering program at the University of Saskatchewan has included core third and fourth-year lab courses (ME 318, ME 328 and ME 418). One of the main objectives of the lab program is for students to identify strengths and weaknesses of theoretical models through comparison to measurements made in the labs. Another is for students to collect, analyse, and interpret data and form appropriate conclusions. Students learn to identify unsuccessful experiments and unrealistic measurements, and calculate uncertainty of measurements. They develop communication skills through lab reports and learn to keep a clear and complete logbook. Teamwork is emphasized, as well as identifying health and safety concerns, and demonstrating professional ethical standards.

One faculty and one or two technical staff members serve as co-coordinators for each of the three courses. Each of the three courses have consisted of approximately 9-10 individual labs, each of which is assigned to a faculty member and a technical staff member, who work together to develop and annually review the lab handout, and to mentor a teaching assistant (TA), who demonstrates the lab, and marks student logbooks and reports. The faculty member also develops and marks final exam questions.

Individual labs have typically been organized into the three lab classes based on the term in which material is covered in core courses. For example, during the term that students take the department's third-year heat transfer course, they have also taken labs dealing with temperature measurement, thermal conductivity and heat exchangers. There have also been some labs that represent the major coverage of a particular topic in the program (e.g., nondestructive testing). Students have been arranged in groups of four, and in most of the labs two of these groups do a particular lab during a three hour session. Figure 1 provides an example of two groups conducting a lab with a TA.

On one hand, dedicated lab classes are valuable as they allow the department to offer a large, diverse set of labs with relatively small lab groups in limited laboratory space. However, one major concern with this approach has been scheduling given that these labs traditionally involve one large piece of equipment. In some case, this equipment may not be able to be used at the same time as another piece of equipment in the same space, which impacts scheduling. For a typical enrolment of 84 students, it will take at least 11 lab sessions for all students enrolled in the course to do an individual lab, with any given lab being run over several weeks to accommodate everyone. Some labs can only be conducted by one group at a time, such as two manufacturing labs that are taught by personnel in Engineering Shops. Often, some or all of the groups do a lab ahead of the material being covered in the core course. With each student completing two formal lab reports, scheduling must provide enough time for students to complete all their formal reports before classes end. This schedule also affects TA's graduate courses and research.

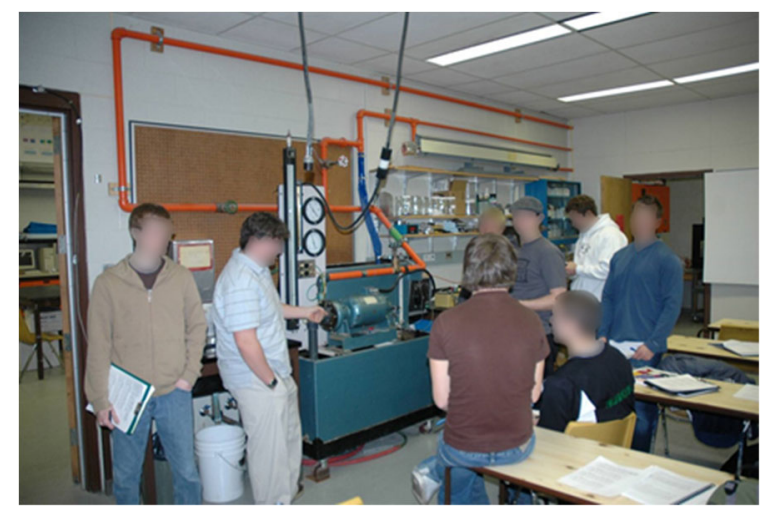

Fig. 1. Previous pipe flow network lab

In addition to scheduling limitations, the singleapparatus model represents a single-point-of-failure risk. Over the last several years there have been cases where needed equipment has failed without backup options or funds to replace it, frustrating students, staff and faculty. While some labs have seen changes over the past decades, not all have kept pace with changes in measurement technology and training in those tools.

There have been a number of developments in these lab courses over the years. For instance, to provide students with additional experience in communication and research, a literature review assignment was included in ME 318 or ME 328. Students picked a topic from a list of suggestions provided by faculty, discussed this topic with the faculty member and then prepared a four to five page report, based on peer-reviewed publications. Efforts have been made to include topics related to environmental and social impact to increase exposure to relevant graduate attributes [1]. An annual TA training program for those demonstrating labs was added in 2014, which has provided a more systematic approach for training TA's, resulting in more consistency in lab demonstrations and grading from lab-to-lab. This approach also made it easier to transition from in-person labs to remote labs during COVID-19.

The department has added labs dealing with wind and solar energy. While these labs have exposed students to alternative energy systems, and in the case of the solar energy lab, are more open-ended, they also illustrate another scheduling complication, as both are dependant on weather conditions. These labs have been scheduled as early as possible in fall term or as late as possible in winter term. Nevertheless, students sometimes are not able to gather quality data because of low wind speeds or cloudy conditions. On one occasion the department paid for snow removal to allow students to access the wind turbine. A lab has also been developed to provide students with an 
opportunity to conduct a finite element analysis and to compare their results to measurements made in the lab.

This paper will discuss the development of a laboratory task group, and its role in the department's continuous improvement process. It will focus on a major review of the lab program and resulting curriculum development. The task group also played a key role in the development of a new lab course, which was first delivered in 2019-20. The important role that the group played in the movement to remote labs during COVID-19 is also discussed.

\section{LAB TASK GROUP}

There have been periodic reviews over the history of the core lab courses. For instance, a major review of the labs was conducted in 2007, including an assessment of safety measures taken in the individual lab sessions. As part of this exercise, procedures for logbooks were changed; students handed in their logbooks at the end of the lab period rather than the following day. As university-level student survey tools only ask for student ratings and comments about an overall course, dedicated surveys in these courses have been conducted since 2008 using online tools developed by the university or outside vendors (e.g., Survey Monkey). Students are asked to rate and comment on general course organization and processes, assistance provided by faculty and attention to safety. For each lab, students evaluate the overall quality of the material covered. The department also has an annual exit survey in which graduating students are asked to comment on strengths and weaknesses of their program. In the past students have identified these lab courses as a strength.

In 2015, a task group, consisting of the department head and course coordinators, was set up to conduct a major review of the three lab courses. This task group reported to the department's undergraduate committee. The group first surveyed how labs were delivered in 16 other programs within Canada, including those within the same geographic region, using program information on their websites. It was determined that the split between programs that used dedicated lab courses and those with lab components in individual core courses was approximately half and half. The group proceeded under the assumption that the department would retain its dedicated lab courses.

The group reviewed the scheduling of labs, links between material in core courses and labs, and the deliverables for each course (including exams, logbooks and reports). A survey for the individual labs was developed by the group and then conducted by the technical staff member who served as each course's cocoordinator. This survey identified the main objective(s) of each individual laboratory, coverage of general experimental design/analysis concepts, major equipment and engineering tools used in each lab, the relationship to core courses, the number of students per lab, and the estimated number of students who were active at any one time. Linkages to CEAB graduate attributes (investigation and use of engineering tools) [1] were identified, with consideration given to challenges in properly assessing these attributes. Historical data (e.g., average marks on logbooks, formal reports and final lab exam questions for that lab), feedback from lab evaluations and the annual exit survey of graduating students were also examined, and potential changes to each lab were identified.

A more general survey of faculty members was also conducted to identify what they felt were the overall objectives of the lab program, the main strengths and weaknesses, and the relationship between the material they cover in core courses and its coverage in labs. As in other faculty surveys $[2,3]$, there was no agreement on a single main objective for labs. Opinion was almost evenly split as to whether the main objective of the lab program was to illustrate theory or teach experimental skills. They were asked about the coverage of more theoretical concepts, and general experimental methods and design. Faculty identified what they felt were the most important experimental skills students would need for a career in research or in industry, and for topics (theoretical or experimental design) that were currently missing from the lab courses. A portion of the department's annual retreat was dedicated to the discussion of the survey results, particularly the balance between the use of labs to illustrate theory and to teach experimental design and other skills.

The group produced an initial report, which was discussed by the undergraduate committee and then the entire department. Some initial changes were made in response to these surveys, including moving individual labs to better align with core courses. Information was added to lab manuals to help students better identify where the theory for each lab was covered in core courses. Many individual write-ups in the lab manual were revised. Coverage of experimental methods, such as conducting an uncertainty analysis was also strengthened within labs.

\section{CONTINUOUS PROGRAM IMPROVEMENT}

After this initial review, the task group was assigned a major role in the department's continuous improvement program. The group meets several times a year, typically from January to May, to review the lab courses and individual labs, using information gathered from the dedicated student lab evaluations and feedback from those responsible for each lab. A system has been set up to monitor and review comments from year to year. For example, the percentage of students who felt that the quality of material within an individual lab was good or very good is tracked, along with the same percentages for general questions related to course organization and procedures, safety, and assistance from faculty. Potential changes to labs are identified, including capital equipment 
purchases, and an action item list is generated. The impact of these action items is reviewed the following year in light of student survey results. In some cases, changes resulted in very significant improvements in survey results.

Each March, the group develops the list of labs that will be offered the following year, which is then used in the assignment of duties process to identify a faculty member for each lab. During this process, some labs are retired, especially if the main equipment used in the lab reached the end of its useful life. Other labs have been moved to second-year courses, which have dedicated labs associated with them. Occasionally a lab may get to share a sabbatical leave with the faculty member responsible for it.

The department has seen the benefit of maintaining this task group in order to provide a structure for continuous program improvement for this very important part of the program. For example, the group is able to conduct a more thorough review of student lab evaluations than the undergraduate committee, given this committee's other responsibilities. As three or four members of the group are Departmental Assistants, this allows for more direct involvement by technical staff members, who take a major role in the coordination, development and delivery of the labs. It has been found that this task group has increased the coordination between the three courses, and changes to one course can be more easily implemented the following year in other courses. For example, ensuring that expectations for the work students do in their logbooks are consistent with the three hours they have to complete this work during the lab is easier to address in the task group as compared to trying to address this on a lab-by-lab basis.

Many members of the task group also sit on the committee that allocates the department's annual capital equipment funding, which has helped to identify and acquire lab equipment that has made a significant difference in the student learning experience. For larger investments, the group takes an important role in applications to other funding opportunities. It has also helped the department respond to challenges that arise, as will be discussed in light of COVID-19 later in this paper.

\section{CURRICULUM DEVELOPMENT}

The lab task group led a major redesign of the common lab program, which is expected to improve delivery and scheduling of these courses, alignment between when material is covered in core courses and labs, workload for students, and experience gained by graduate TA's. In 2017, the department conducted a review of its program as part of a college strategic enrolment management project. This included comparing course requirements with other programs in Western Canada, which indicated that the students had a heavier course load than in these other programs (e.g., in third year students took 14 courses, including two lab courses). Attrition/failure rates were relatively high in the second and third year, even though there was high demand for the program from students when they selected their discipline after a common first year.

While the three laboratory courses were seen as strengths, it was also acknowledged that the way that the labs were run could limit the number of students in the program. Therefore, the department felt it should examine different models for delivering the material in the third and fourth-year lab courses. As the structure of these labs limited the number of students in these courses, changes could help the program to grow in the future.

The department also examined prerequisites and corequisites in order to streamline the program for students. In particular, this was expected to benefit the large number of students who decide to complete their program over five years, especially if they failed any second-year courses. Changes were also expected to improve timetabling of third and fourth-year courses, and to address concerns related to student workload, mental health, part-time employment, and school-work-life balance. A much simpler prerequisite system was developed, especially for core lab courses.

As a result of this study, the department decided to reduce its program by two courses, beginning in 2019-20, bringing course requirements more in line with other programs that were surveyed. One of the core courses was changed to a technical elective, and it was decided to amalgamate the three lab courses into two - one in the second term of third year (ME 328) and one in the first term of fourth year (ME 418). The department planned to eventually remove a third course, which would result in students taking six courses per term for the last three years of the program. This goal will be reached with the advent of a new first-year program and subsequent changes to the mechanical engineering program, beginning in 2021-22.

The reduction in the number of lab courses was expected to decrease the total number of lab sessions. However, given the gains in scheduling and resource-use efficiency that will be discussed, this reduction was not expected to be drastic. For example, in 2018-19, 27 labs were offered in the three courses, and students required two three-hour blocks in their timetable each term. By more efficiently scheduling labs students should be able to use 24 to 26 slots for labs in the two courses, even if they only register in one three-hour block each term. By having one lab course in each of the final two years, offering these courses twice per year would be possible, increasing flexibility for students and removing one barrier for increasing enrolment. Some topics that may have had a dedicated lab could be better delivered by incorporating them as common threads running through several labs, which would improve the student experience. 


\section{LAB Program Redesign}

The lab task group was expected to lead this major redesign of the lab program, which, as noted previously, was expected to improve delivery and scheduling of these courses, alignment between when material is covered in core courses and labs, workload for students, and experience gained by graduate TA's. As noted earlier, many existing labs involved a group of between four and eight students using one single large piece of equipment at a time; multiple, smaller, less expensive versions of the equipment were identified as a means of reducing group size while simultaneously increasing lab throughput. Unlike previous practice, this approach would also allow all students to complete the labs in the same order, meaning labs could be designed to build on one another to more systematically improve students' general laboratory skills, including the use of data acquisition systems and experimental design. This would also make it possible for all students to perform an individual lab in the same week, making the coordination between lab and course material far easier. This new approach was used for the first time in ME 328 in 2019-20.

The group first examined the list of the department labs (Table 1) to determine which topics should be included in the new version of ME 328, based on the topics they covered and the potential for multiple lab stations. Some labs previously included in third year, which relied heavily on a single piece of equipment (e.g., the wind turbine in Fig. 1), were moved to ME 418. The group also looked at ways to increase exposure to instrumentation and computing for measurement, investigation and analysis.

Table 1: List of labs in ME 318, ME 328 in 2018-19

\begin{tabular}{|c|l|l|}
\hline & ME 318 & ME 328 \\
\hline 1 & $\begin{array}{l}\text { Microstructure of Ferrous } \\
\text { Alloys }\end{array}$ & Hardenability \\
\hline 2 & Wind Turbine $^{*}$ & Welding Metallurgy $^{*}$ \\
\hline 3 & Temperature Measurement & Pipe Networks \\
\hline 4 & Control \& Data Acquisition $^{*}$ & Wind Tunnel \\
\hline 5 & $\begin{array}{l}\text { Thermal Conductivity \& } \\
\text { Resistance }\end{array}$ & Heat Exchanger \\
\hline 6 & Intro. to Manufacturing I & Cantilever Beam \\
\hline 7 & Intro. to Manufacturing II & Bolt Preloading \\
\hline 8 & Strain Gauge Mounting & Failure Analysis \\
\hline 9 & Wheatstone Bridge Circuits & Literature Review \\
\hline 10 & FEM Modeling of a Beam & \\
\hline 11 & Strain Gauge Rosettes & \\
\hline 12 & Non-destructive Testing & \\
\hline
\end{tabular}

* to be moved to ME 418

The lab task group also discussed the possibility of including a set of optional labs in ME 418. As technical electives are offered on a rotating, two-year cycle, this would provide students an opportunity to gain experience in these areas in years a particular elective is not offered.
While the manufacturing labs were included in ME 328 in 2019-20, the department is looking for a more permanent home. One option would be a second-year materials and manufacturing course, allowing students to gain hands-on experience before starting the ME 229 second year design project course. Increasing hands-on experience for students is consistent to changes made to ME 229 to increase the emphasis on prototyping [9]. The department has also introduced ME 329, a third-year design course, in which students design and manufacture a mechanism in a group environment, using parts manufactured with $\mathrm{CNC}$ tools.

While the initial emphasis has been on ME 328, the lessons learned in the development and delivery of this modified course will also be applied in the future to redesign labs in ME 418. While some of the fourth-year labs may more difficult to move to smaller lab stations, making changes to some labs in this courses will help to address scheduling issues for students and TA's, and allow better coordination between ME 418 labs and when material is covered in core fourth-year courses. It is also expected that this redesign will also identify topics, which are currently covered in lab courses, which may be better covered through the use of videos, demonstrations and assignments in core courses.

\section{ME 328 COURSE REDESIGN}

While it was expected that topics included in the new ME 328 would be similar to those covered in the former lab courses (Table 1), the course was redesigned starting with learning objectives and links to graduate attributes. The redesign was also informed by experience from an instrumentation course taught by the faculty member who co-coordinated the course, and a previous trial with a wheatstone bridge lab he redesigned for ME 318 . The revised list of ME 328 labs is shown in Table 2.

Table 2: List of labs in redesigned ME 328 in 2019-20.

\begin{tabular}{|c|l|}
\hline Lab & Lab Title \\
\hline 1 & Microstructure of Ferrous Alloys \\
\hline 2 & Hardenability \\
\hline 3 & $\begin{array}{l}\text { Introduction to Data Acquisition and } \\
\text { Resistive Sensors }\end{array}$ \\
\hline 4 & $\begin{array}{l}\text { Heat Exchangers, Temperature } \\
\text { Measurement and Thermocouples }\end{array}$ \\
\hline 5 & Thermal Conductivity and Uncertainty \\
\hline 6 & Dynamic Measurement and Phase \\
\hline 7 & Flow Networks \\
\hline 8 & Bolt Preloading \\
\hline 9 & Measuring and Visualizing Strain Fields \\
\hline 10 & Wheatstone Bridges and Load Measurement \\
\hline 11 & Independent Investigation (week 1) \\
\hline 12 & Independent Investigation (week 2) \\
\hline
\end{tabular}

The new ME 328 course was built around having multiple instances of lab apparatus. Every group in the lab 
section had their own workstation, allowing multiple groups to conduct the same lab at the same time. Core elements of these workstations (computer and data acquisition systems (Fig. 2)) are used in most labs throughout the term, facilitating incremental skill and proficiency development. This consistency is key to moving students from focusing on the mechanics of using these tools, to using the tools to engage with the content.

For the first offering in Winter, 2020, the target was six workstations, which limited groups to a maximum of four students. While not ideal, it was still a significant improvement over past practice, and a staged roll-out will help lower costs associated with changes needed after the first year. Funding for the first set of workstations and lab equipment came from the department's capital equipment allotment, a grant from the college's Engineering Advancement Trust, and individual donors. The eventual goal is to have 12 fully-equipped workstations, which could accommodate up to 120 students per week while limiting groups to two students, ensuring that every student is able to more actively engage in the lab than in previous years. It is also anticipated that some equipment will also find use in second-year labs (e.g., fluid mechanics, material science), and be available as a resource to students in design courses and student design teams.

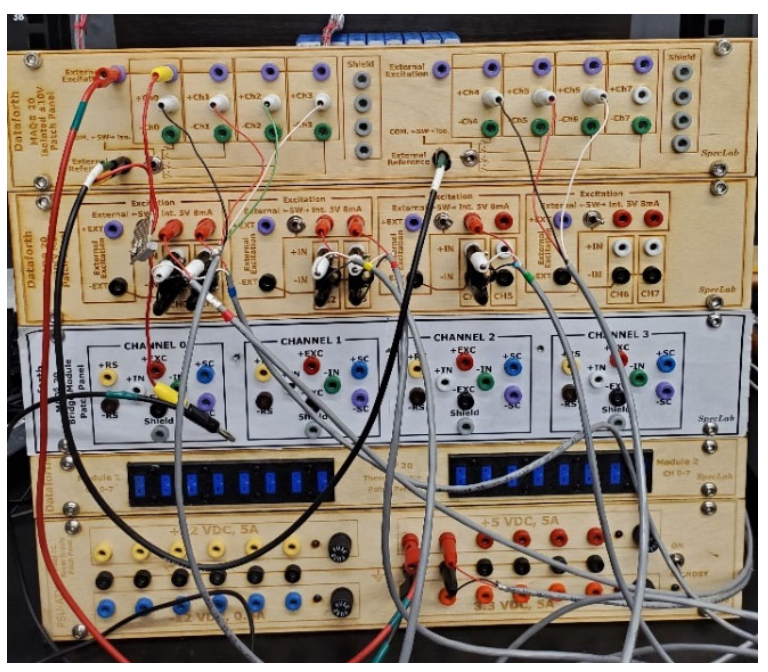

Fig. 2. ME 328 data acquisition system.

Having multiple workstations of replicate apparatus allows the lab to scale in size, and for all students to complete the same lab in the same week, making it easier for instructors to synchronize lecture and lab content. As an example, Fig. 3 shows the new version of the pipe network lab. Having enough equipment for a class also removes the time pressures that come with too many groups sharing a single piece of equipment. Where the previous delivery model had different labs running in multiple spaces (often shared with or adjacent to research space) at the same time, the new approach allowed nearly all the labs to be conducted in one space.

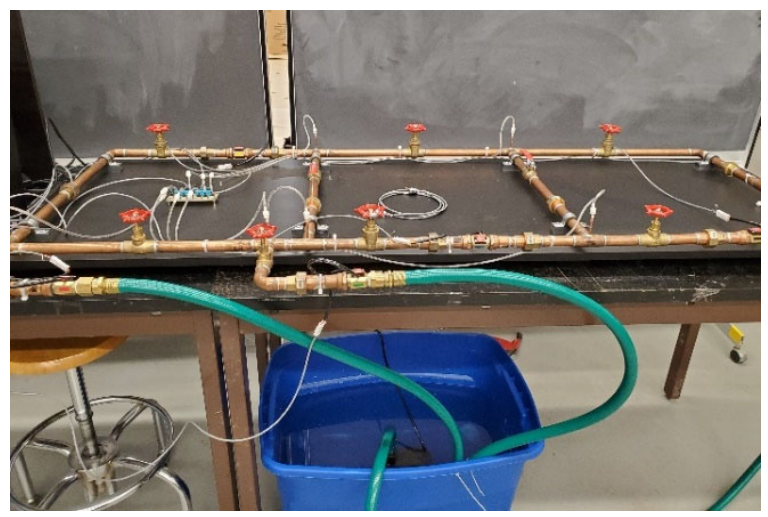

Fig. 3. Modified ME 328 flow network apparatus.

A comparison of course components and grading schemes in ME 328 before and after the redesign is shown in Table 3. Different types of deliverables were used, rather than just logbooks and formal lab reports. For most labs, students produced a short memo to summarize the results of labs, as if they were summarizing a series of tests in the field for their supervisor. The logbook was used as a tool to record observations and data, rather than as a mini-lab report, as had been done in the past. In many cases students were given scenarios to develop their memos around, such as in Lab 7 when they were asked to provide an assessment to their supervisor of a spreadsheet-based program for doing calculations for the pipe network shown in Fig. 3.

Table 3: Comparison of grading schemes in ME 328 before and after redesign.

\begin{tabular}{|l|c|l|c|}
\hline \multicolumn{2}{|c|}{ 2018-19 } & \multicolumn{2}{c|}{ 2019-20 } \\
\hline Component & \% & Component & $\%$ \\
\hline Logbooks & 20 & Logbooks & 15 \\
\hline $\begin{array}{l}\text { Formal Reports: } \\
\text { 2 individual }\end{array}$ & 20 & $\begin{array}{l}\text { Formal Reports: } \\
\text { 1 individual, 1 group }\end{array}$ & 25 \\
\hline Final Exam & 50 & Final Exam & 30 \\
\hline $\begin{array}{l}\text { Literature } \\
\text { Review }\end{array}$ & 10 & $\begin{array}{l}\text { Quizzes (pre-lab), } \\
\text { Assignments, Memos }\end{array}$ & 10 \\
\hline & & Group Project & 20 \\
\hline
\end{tabular}

After gaining initial experience in Lab 3 with the data acquisition system shown in Fig. 2, students continued to use this equipment in subsequent labs. This was different from the previous approach where there may be a different system for each lab, which in some cases was operated solely by the TA. The labs were designed to allow students to continue to build on skills learned in previous labs. One example is Lab 4 where students learned to build thermocouples. These thermocouples were then used in the later part of the lab to measure heat exchanger performance, and then the following week to measure temperatures and heat fluxes, as part of the procedure to determine thermal conductivity. Lab 5 is also an example 
of where students were asked to compare the results of hand calculations with their measurements; temperatures calculated using exact solutions for transient and steadystate heat transfer were compared with those measured in different types of insulation and composite mini-walls heated using a hot plate. Students also completed a group report in Lab 5 in which they compared their results to other groups and determined the uncertainty in their measurements. While several methods of temperature measurement included in the previous lab are no longer covered, it was felt that these could still be effectively covered during lectures in the core heat transfer course.

A key addition to ME 328 was the self-directed lab, in which students formed a group and identified a particular question they wished to investigate. They prepared a memo to the course co-ordinators outlining the topic of their investigation, the parameters that they felt were important, and their hypothesis. They then developed a lab proposal (which would be similar to the lab manual entries), and described a refined question, hypothesis, procedure and apparatus (including any safety issues), and a test matrix. A literature review was also included. As students currently have two scheduled blocks of time each week for this course (and in many weeks will only use one), they could use this time throughout the term to prepare for the last two weeks of class, which were dedicated to conducting the tests for the project and preparing the project report. Unfortunately, students were not able to complete the self-directed lab in March, 2020 when the university moved to remote delivery of classes. Plans were quickly made to complete the course and develop a bank of multiple-choice questions for the lab final exam, which was administered using the Blackboard learning system.

As a large number of pieces of equipment had to be manufactured for these labs and the lab manual was completely rewritten, some of this work was completed "just-in-time" in 2020. As all of the work stations were being used by students, TA's could not be trained for a particular lab until the previous lab ended and the equipment for the new lab was put in place. Some of these issues were reflected in student comments about the course and individual labs (Fig. 4). In the future an additional work station will be created to allow training to take place the week prior to the specific lab that TA's are assisting with. Based on student feedback, the group also decided to refine the expectations for each lab, as well as rubrics for logbooks, memos, reports and other coursework. The task group decided to wait until after the course had been run twice before scaling up the number of lab stations and/or making any significant changes to equipment. As the course was offered remotely in 2020-21, this may need to wait until after the 2021-22 offering.

Student comments on the overall philosophy of the course (e.g., increased hands-on learning) were positive, and $70 \%$ of students felt they had the skills needed to complete labs. Most students felt pre-lab and post-lab quizzes and assignments were effective (79\% and $70 \%$, respectively). $70 \%$ of students indicated that the memos helped them develop their report writing skills. Even though they were not able to complete a self-directed lab, students recognized the value of this component. The task group will continue to look for opportunities to develop and reinforce skills (e.g., data acquisition) in ME 328.

Despite all the challenges associated with this major redesign, feedback from students on the first offering of the course was considered to be generally positive, with students recognizing the potential for this course. The average percentage of students who rated the material as good or very good in a particular lab session was $75 \%$ (Fig. 4). For five of the nine labs (the last three labs had been scheduled for after the move to remote delivery) this percentage was higher than $80 \%$ and for two of these labs it was higher than $90 \%$. Comments on the individual lab sessions were also reviewed and a list of action items was developed for each, including deleting or adding activities depending on the time required to compete labs.

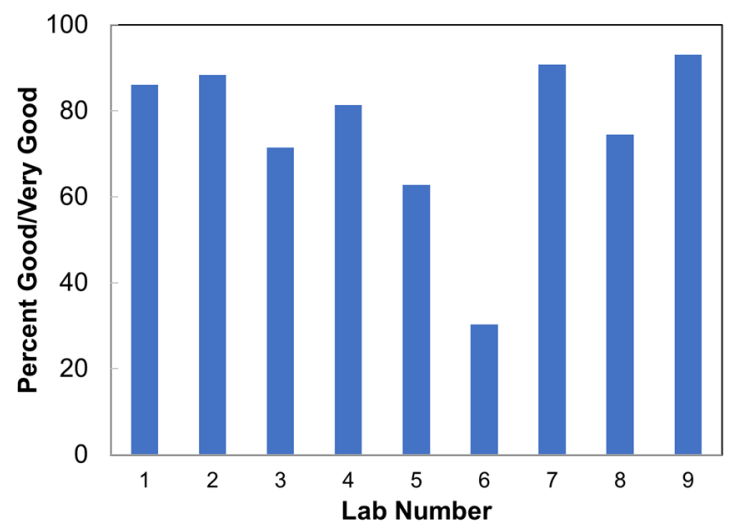

Fig. 4. Student ratings for individual ME 328 labs in 2019-20 (see Table 2 for lab titles)

\section{COVID-19 AND REMOTE LABS}

One major benefit of having this lab task group was that it made it easier for the department to quickly move to remote labs in March, 2020 at the start of the COVID-19 pandemic. Considerable effort was then made by the group in the spring and early summer to select labs for 2020-21, to consider different forms of remote delivery, and to organize tasks associated with preparation of videos and other materials. This helped staff and faculty to more quickly start this work once access to the building began in the latter part of June, 2020.

Stronger coordination between the labs has also assisted with the delivery of remote labs in 2020-21. In ME 328 and ME 418, students viewed videos that were posted in advance of lab periods, which were scheduled in a similar 
way to in-person labs in the past. However, these sessions could be more easily scheduled to coincide with when material was covered in core courses. Students were expected to attend the online lab session at a particular time, where they met with the TA to discuss any questions about the lab, and to work as a group on the lab. One advantage of filming labs that still rely on larger pieces of equipment is that there are now backups if equipment fails.

There have also been a number of courses in the department in 2020-21 in which synchronous online labs were held. For example, in one fourth-year elective two live video cameras provided students with an overview and a close-up view of the test, and students interacted with the TA conducting the experiment. In another elective course, simulation software was used to replicate the behaviour of a microcontroller that would be used in the in-person lab. In the ME 329 collaborative design course a staff member served as the students' avatar, taking instructions from the remote students as he operated a piece of $\mathrm{CNC}$ equipment.

\section{CONCLUSIONS AND FUTURE WORK}

This paper has described the structure of a department lab task group, and its roles in continuous improvement, including major reviews of the lab program, and annual reviews of student evaluations and individual labs. The group was tasked with amalgamating the department's three dedicated lab courses into two, after curriculum changes were made to reduce course requirements. The group has begun a redesign of the lab program to move from the use of single, large pieces of equipment to a larger number of student workstations to improve lab scheduling and improve the student experience. In 2019-20, the department introduced a redesigned third-year lab course based on this philosophy. Feedback on this initial offering was generally positive. With the move to remote delivery of classes during the COVID-19 pandemic, the task group has taken a major role in the development of remote labs, most of which contain a synchronous component. When inperson classes resume, the task group is expected to continue to work towards its longer-term goal of redesigning many of the ME 418 labs so students in a lab section can complete these during the same week using smaller versions of lab equipment. This will also provide further opportunities to continue to develop and apply the experimental skills learned in ME 328.

\section{Acknowledgements}

Financial support for the redesigned laboratory course from the University of Saskatchewan's College of Engineering, the Department of Mechanical Engineering, Engineering Advancement Trust and individual donors is gratefully acknowledged. The authors would also like to thank Mike Miller, Shawn Reinink and Nanfang Zhao for their technical assistance with changes to labs, the many faculty members who developed new or revised labs over the last several year, and the graduate students who served as teaching assistants in these courses. They would also like to thank Profs. David Sumner and Akindele Odeshi (Undergraduate Chairs) and Prof. Jim Bugg (Department Head) for their support of the task group and lab redesign project. Finally, the role that undergraduate students and graduate teaching assistants have played in the continuous improvement process is gratefully acknowledged.

\section{References}

[1] Canadian Engineering Accreditation Board, 2020 Accreditation criteria and procedures. Engineers Canada, Ottawa, ON, 2020.

[2] P. Coppens, J. Van den Bossche and M. De Cock, "Goal of lab work in electronics: student and staff ideas," International Journal of Electrical \& Engineering Education, vol. 53, pp. 124-136, 2016.

[3] N.E. Edward, "The role of laboratory work in engineering education: student and staff perceptions," International Journal of Electrical \& Engineering Education, vol. 39, pp. 11-19, 2002.

[4] L.D. Feisel and A.J. Rosa, "The role of the laboratory in undergraduate engineering education," Journal of Engineering Education, vol. 94, pp. 121-130, 2005.

[5] R.M. Felder and R. Brent, "Designing and teaching courses to satisfy the ABET engineering criteria," Journal of Engineering Education, vol. 92, pp. 7-25, 2003.

[6] T. Fuhrmann, R. Mandl and M. Shamonin, "Analysis of learning improvement on changing lab course from single experiments to projects," International Journal of Electrical \& Engineering Education, vol. 52, pp. 287-297.

[7] M. Hastie and J. Haelssig, "An open-ended design-based lab exercise for a first thermofluids course," in Proc. CEEA Canadian Engineering Conf., CEEA16, (Halifax, NS; 19-22 June), pp. 5, 2016.

[8] J. Lemay, "The inverted/integrative/open lab course: a mechanical engineering lab example," Proc. CEEA Canadian Engineering Conf., CEEA19, (Ottawa, ON; 9-12 June), 6 pp., 2019.

[9] R. Retzlaff, R. Burton and D. Torvi, "Teaching Engineering Accountability through Physical Prototyping," Proc. CEEA Canadian Engineering Education Conf., CEEA14, (Canmore, AB; 9-11 June), 6 pp., 2014.

[10] R.F. Schkoka, T.A. Schweisinger and J.R. Wagner, "An improved undergraduate mechanical engineering laboratory structure and curriculum: design and assessment," Internatinal Journal of Mechanical Engineering Education, vol. 40, pp. 182-196, 2012.

[11] M.J. Zhang, C. Newton, J. Grove, M. Pritzker and M. Ioannidis, "Design and assessment of a hybrid chemical engineering laboratory course with incorporation of studentcentered experiential learning," Education for Chemical Engineers, vol. 30, pp.1-8, 2020. 